\title{
Biosynthesis of medium chain length poly-3-hydroxyalkanoates by Pseudomonas guezennei from various carbon sources
}

\author{
Christelle Simon-Colin ${ }^{a,{ }^{*}}$, Gérard Raguénès ${ }^{a}$, Bernard Costa $^{b}$ and Jean Guezennec ${ }^{a}$ \\ a Institut Français de Recherche pour l'Exploitation de la Mer, Centre de Brest, BIOMAR/BMM, BP 70, 29280 \\ Plouzané, France \\ ${ }^{b}$ Biolib, B.P. 14521, 98701 Arue, Tahiti, Polynésie Française, France
}

*: Corresponding author : Christelle Simon-Colin, email address : Christelle.Simon.Colin@ifremer.fr

\begin{abstract}
:
The biosynthesis of poly-(3-hydroxyalkanoates) (PHAs) by Pseudomonas guezennei using glucose and/or fatty acids with chain-length from 3 to 18 carbon atoms as carbon sources was investigated. Glucose, acetate, pyruvate, propionate, valerate, hexanoate, heptanoate, octanoate, decanoate, and oleic acid were supplemented in the mineral medium as the sole carbon source or as a mixture for PHAs accumulation. Chemical composition of the resulting PHAs was analysed by coupled gas chromatography mass spectroscopy (GCMS), Fourier Transform Infrared Spectroscopy (FTIR) and nuclear magnetic resonance spectroscopy (NMR). PHAs contained up to 10 different types of 3hydroxyalkanoic acid units, including saturated 3-hydroxyacids from $\mathrm{C} 4$ to $\mathrm{C} 14$, and unsaturated monomers as 3-hydroxydodecenoate (3HDde) and 3-hydroxytetradecenoate (3HTde). 3Hydroxydecanaote (3HD) and 3-hydroxyoctanaote (3HO) were incorporated preferentially except during cultivation on heptanoic acid, when P. guezennei synthesized PHAs with a higher concentration of 3-hydroxyheptanoate $(3 \mathrm{HHp})$. Thermal analysis indicated semi-crystalline polymers with melting temperatures $(\mathrm{Tm})$ ranging from 42 and $51^{\circ} \mathrm{C}$, fusion enthalpy $(\Delta \mathrm{Hm})$ comprised between 4 and 22 $\mathrm{J} / \mathrm{g}$, and glass transition temperatures $(\mathrm{Tg})$ from -41 to $-50^{\circ} \mathrm{C}$. Crystallinity index $(\mathrm{Cl})$ as deduced from FTIR spectra showed values comprised between 0.32 and 0.37 . Molecular weights as determined by gel permeation chromatography (GPC-MALLS) ranged from 64200 to $390000 \mathrm{~g} / \mathrm{mol}$.

The results obtained from this study indicate that $P$. guezennei is capable of producing a variety of medium chain length (MCL) PHAs via de novo fatty acid biosynthesis and $\beta$-oxidation depending on the nature of the carbon source supplied.
\end{abstract}

Keywords: Polyhydroxyalkanoates; Polymer characterization; Pseudomonas guezennei; Carbon substrates 


\section{Introduction}

Owing to their thermoplastic properties and biodegradability, PHAs have attracted industrial interest, and have been extensively studied over the last two decades (reviewed in 1-4 and references cited therein). PHAs comprise a large class of polyesters that are accumulated in a wide variety of bacteria as carbon and energy storage material. Polymers are deposited intracellularly in the form of inclusion bodies ("granules"), and might amount up to $90 \%$ of the cellular dry weight $[3,5,6]$ when bacteria are cultivated in the presence of carbon excess and if one nutrient limits growth [7]. The monomeric composition of PHAs depends both on the bacterial strain and on the carbon source supplied. PHAs can be divided into three groups depending on the number of carbon atoms in the monomeric units: short-chain-length PHAs (3-5 carbon atoms, PHAs scL), medium-chain-length (6-15 carbon atoms, PHAs $\mathrm{MCL}$ ) and longchain-length (more than 15 carbon atoms, PHAs ${ }_{\text {LCL }}$ ). Bacterial PHAs are probably the largest group of thermoplastics known and their properties are similar to those of petrochemicals plastics, including material that resemble polypropylene and others that are elastomeric. Typically, PHAs with short-chain-length such as poly-3hydroxybutyrate $(\mathrm{P} 3 \mathrm{HB})$ are highly crystalline, rigid, and brittle, with poor elastic properties, limiting their range of applications. At the opposite, PHA MCL are semicrystalline elastomers with a low melting point, low tensile strength and high elongation to break ie are more ductile and easier to mold.

In addition to being tremendous potential substitutes for conventional plastics, PHAs can be produced naturally from renewable resources and represent a new way of utilizing waste from low cost carbon stocks [8-12]. However, the most attractive feature of PHAs is their biodegradability into $\mathrm{CO}_{2}$ and $\mathrm{H}_{2} \mathrm{O}$, resulting from the pure chirally R- 
configuration that makes PHAs a source of renewable and environmentally friendly plastics.

Fluorescent pseudomonad strains belonging to the rRNA homology group I are able to synthesize PHAs MCL [13-15] from co-enzyme A thioesters of the hydroxyalkanoic acids, which are synthesized during fatty acid metabolism. Actually, the PHAs biosynthestic route is connected to fatty acid metabolism pathways either via fatty acid catabolism or anabolism. PHAs that accumulate during growth on fatty acids are synthesized from degraded fatty acids via $\beta$-oxidation cycle and consist of monomers with the same chain length as the substrate or of a length which is one or more $\mathrm{C} 2$ units shorter than the substrate $[6,14,16]$. De novo fatty acid biosynthesis is the main route for PHAs accumulation during growth on simple compounds such as glucose $[15,17,18]$. When precursors are obtained via de novo fatty acid synthesis PHAs formation is characterized by the presence of monomers differing by two carbon atoms and/or contained unsaturation. Both $\beta$-oxidation and fatty acid biosynthesis can function independently and simultaneously to supply precursors for PHAs biosynthesis [19].

In this study we investigated the ability of Pseudomonas guezennei, a newly described bacterium isolated from microbial mats growing on Polynesian atolls [20], to produce various types of PHAs copolymers during growth on related and non-related substrates. In this report, we focused on the relationship between PHAs biosynthesis and fatty acid metabolism in this bacterium. Detailed GC-MS and NMR analyses revealed PHAs copolymers with both saturated and unsaturated 3-hydroxy-fatty acids. Moreover, DSC, GPC-MALLS and FTIR analyses were used to study thermal and physical properties of these polymers. 


\section{Methods}

\subsection{Bacterial strain and media for PHA production}

Pseudomonas guezennei (strain CNCM I-3358 in the Collection Nationale de Cultures de Microorganismes, Institut Pasteur, Paris, France) was cultivated in $200 \mathrm{ml}$ of sterile Marine Broth medium (15g/l of sea salts, $5 \mathrm{~g} / 1$ peptone, $1 \mathrm{~g} / 1$ yeast extract, $\mathrm{pH}$ adjusted at 7), in $500 \mathrm{ml}$ erlenmeyer flasks, using a $10 \%(\mathrm{v} / \mathrm{v})$ inoculum of suspended cells in exponential phase of growth. The culture was incubated on a rotary shaker at $200 \mathrm{rpm}$ at $34^{\circ} \mathrm{C}$ overnight. The cells were harvested by centrifugation $(8000 \mathrm{xg}$ for $10 \mathrm{~min})$, the pellet was dispersed and transferred to a $500 \mathrm{ml}$ flask containing $200 \mathrm{ml}$ medium composed as followed : $15 \mathrm{~g} / \mathrm{l}$ of sea salts, $0.4 \mathrm{~g} / \mathrm{l}$ yeast extract, and one of the following carbon sources. Acetate, pyruvate, propionate, hexanoate, heptanoate, decanoate, and glucose were supplemented at the concentration of $10 \mathrm{~g} / \mathrm{l}$ whereas valerate and octanoate were used at $3 \mathrm{~g} / \mathrm{l}$ and $5 \mathrm{~g} / \mathrm{l}$ respectively. All carbons sources were purchased from Sigma-Aldrich. Following cultivation at $200 \mathrm{rpm}$ at $34^{\circ} \mathrm{C}$ for $60 \mathrm{~h}$, cells were harvested by centrifugation (10 000xg for $15 \mathrm{~min}$ ), washed-up three times with diluted sea-water, and the pellets lyophilised prior to PHAs extraction.

\subsection{PHA isolation and characterization}

Lyophilized cell pellets were ground in a mortar and the resulting powder was extracted with chloroform for $4 \mathrm{~h}$ at $50^{\circ} \mathrm{C}$. The PHA-containing chloroform phase was concentrated and extracted once with water to remove residual solid particles. The organic phase was evaporated to dryness and the resulting crude extract preserved for further analyses. Purified PHAs were obtained by repeated precipitations in 10 volumes of cold methanol.

\subsection{GC-MS analyses}


Samples of polymer were subjected to methanolysis in the presence of $\mathrm{MeOH} / \mathrm{HCl}$ $(17 / 2, v / v)$ at $100^{\circ} \mathrm{C}$ for $4 \mathrm{~h}$ in Pyrex test tubes (volume $10 \mathrm{ml}$ ) with screw Teflon-lined caps. After phase separation and two washes with distilled water, the organic phase was dried under nitrogen. TMSi derivation of 3-hydroxyalkanoates methyl esters was accomplished by adding $100 \mu \mathrm{l}$ pyridine and $100 \mu \mathrm{l}$ BSTFA to $1 \mathrm{ml}$ methanolized sample. The reaction mixture was heated at $70^{\circ} \mathrm{C}$ for $45 \mathrm{~min}$. The TMSi derivatives of methyl esters of monomers constituents were analysed by GCMS using an Agilent $6890 \mathrm{~N}$ chromatograph coupled to a quadrupole Agilent 5975 inert XL mass selective spectrometer, equipped with a HP-5-MS fused silica capillary column (30 m x $0.25 \mathrm{~mm}$, $25 \mu \mathrm{m}$ film thickness). A $1 \mu \mathrm{l}$ sample was injected (spit ratio 100:1) with helium as carrier gas and the temperature was programmed for the separation of peaks $\left(60^{\circ} \mathrm{C}\right.$ for one min, ramp of $4^{\circ} \mathrm{C} / \mathrm{min}$ to $140^{\circ} \mathrm{C}, 15^{\circ} \mathrm{C} / \mathrm{min}$ to $280^{\circ} \mathrm{C}$ and $5 \mathrm{~min}$ at $280^{\circ} \mathrm{C}$ ). The ionising energy for MS operation was $70 \mathrm{eV}$.

\subsection{FTIR analyses}

FTIR ATR spectra were recorded on a Nicolet AVATAR 370 DTGS FTIR spectrometer. Samples of polymer were dissolved in chloroform and deposited as film on Germanium disks. Scans were performed in the range of 600 and 4000 wave number $\left(\mathrm{cm}^{-1}\right)$.

\subsection{NMR analyses}

NMR spectroscopy was performed at $25^{\circ} \mathrm{C}$ on samples of PHA MCL dissolved in deuterated chloroform on a BRUKER $400 \mathrm{DRX}$ spectrometer operating at $400 \mathrm{MHz}$ for

${ }^{1} \mathrm{H}$ and $100 \mathrm{MHz}$ for ${ }^{13} \mathrm{C}$. Chemical shifts are reported in ppm relative to the signal of 2,2,3,3-tetradeutero-3-(trimethylsilyl)-propanoic acid sodium. 


\subsection{DSC analyses}

Differential scanning calorimetry was performed with a TA Instrument 2920 Modulated DSC. Sample of about $10 \mathrm{mg}$ was encapsulated in aluminium pan and heated from $80^{\circ} \mathrm{C}$ to $100^{\circ} \mathrm{C}$ at a heating rate of $10^{\circ} \mathrm{C} \min ^{-1}$ under $50 \mathrm{~mL} \mathrm{~min}{ }^{-1}$ nitrogen purge. The melting temperature $\left(T_{\mathrm{m}}\right)$ and enthalpy of fusion $\left(\Delta H_{\mathrm{m}}\right)$ were taken from the melting endotherm and glass transition temperature $\left(T_{\mathrm{g}}\right)$ was taken as the midpoint of the heat capacity change. The fusion enthalpy of a theorical $100 \%$ crystalline sample was assumed to be $146 \mathrm{~J} / \mathrm{g}$ [21].

\subsection{GPC-MALLS analyses}

Molecular weights were determined by gel permeation chromatography on a system consisting of a 2695 Alliance Module (Waters), three Ultrastyragel columns (HR2, HR4, HR6) placed in series, a 2414 differential refractometer (Waters) and a laser light scattering detector miniDawn Treos (Wyatt Technology Corporation). Tetrahydrofuran (THF) was used as a mobile phase at a flow rate of $1 \mathrm{ml} / \mathrm{min}$. The samples were injected as solutions in THF, filtered through a $0.45 \mu \mathrm{M}$ polytetrafluoroethylene filter and 100 $\mu \mathrm{L}$ of $5 \mathrm{mg} / \mathrm{ml}$ solutions were injected. The value of $d n / d c$ was determined as equal to $0.065 \pm 0.002 \mathrm{ml} / \mathrm{g}$ for PHA mcl in THF at room temperature.

\section{Results and discussion}

\subsection{Characterization of PHAs obtained from P.guezennei}

Purified PHAs synthezised by $P$. guezennei on various substrates were characterized by FTIR, NMR, GCMS, DSC and GPC-MALLS. FTIR spectra of PHAs produced by $P$. guezennei grown on different substrates showed the typical structure of a polyester with 
an intense absorption peak corresponding to the stretching band of the ester carbonyl group $(\mathrm{C}=\mathrm{O})$ at $1725-1740 \mathrm{~cm}^{-1}$, and three intense bands between 2950 and $2962 \mathrm{~cm}^{-1}$ assigned to anti-symmetric and symmetric $\mathrm{CH}_{3}$ and $\mathrm{CH}_{2}$ stretching modes (Fig. 1). The $\mathrm{C}=\mathrm{O}$ stretching band in the $1740-1725 \mathrm{~cm}^{-1}$ region could be assigned to the vibrations of the amorphous and crystalline carbonyl groups respectively [22-23]. Others bands near $1185 \mathrm{~cm}^{-1}$ helped to identify the types of PHAs : short chain length PHAs such as poly- $\beta$-hydroxybutyrate (PHB) shows a band at $1185 \mathrm{~cm}^{-1}$, whereas longer chain length PHAs show a band at $1165 \mathrm{~cm}^{-1}$. A relative measure of the degree of cristallinity can be defined as the ratio of the bands at $1185 \mathrm{~cm}^{-1}$ for PHAs ${ }_{\mathrm{SCL}}$ or band at $1165 \mathrm{~cm}^{-1}$ for PHAs MCL to that at $1385 \mathrm{~cm}^{-1}$ band which is insensitive to the degree of cristallinity [24]. This crystalline index (CI) is not to be confused with the absolute degree of cristallinity but is useful as a comparison criterion [25]. The cristallinity index of PHAs MCL obtained from $P$. guezennei grown on various carbon sources was comprised between 0.23 and 0.37 (Table 1), compared to those of P3HB, $\mathrm{P}(3 \mathrm{HB}-\mathrm{co}-5 \mathrm{~mol} \%$ 3HV) and $\mathrm{P}(3 \mathrm{HB}-\mathrm{co}-12 \mathrm{~mol} \% 3 \mathrm{HV}) \quad 0.94,0.75$ and 0.64 respectively. These results are consistent with previous reports that evidenced that cristallinity had tendancy to decrease when the side chain length increases [24, 26-27]. These results were confirmed by DSC experiments. Melting points of PHAs mcl produced by P.guezennei ranged from 42 and $51^{\circ} \mathrm{C}$, with $\Delta H_{\mathrm{m}}$ from 4 to $22 \mathrm{~J} / \mathrm{g}$, and glass transition temperatures between -41 to $-50^{\circ} \mathrm{C}$. These values were far lower from those found for $\mathrm{P} 3 \mathrm{HB}, \mathrm{P}(3 \mathrm{HB}-$ co-5 mol\% 3HV) and $\mathrm{P}(3 \mathrm{HB}-\mathrm{Ho}-12 \mathrm{~mol} \% 3 \mathrm{HV})$, with $T_{\mathrm{m}}$ and $\Delta H_{\mathrm{m}}$ values of $175^{\circ} \mathrm{C}$ and $95 \mathrm{~J} / \mathrm{g}$ for $\mathrm{P} 3 \mathrm{HB}, 159^{\circ} \mathrm{C}$ and $64 \mathrm{~J} / \mathrm{g}$ for $\mathrm{P}(3 \mathrm{HB}-\mathrm{co}-5 \mathrm{~mol} \% 3 \mathrm{HV})$ and $148^{\circ} \mathrm{C}$ and $59 \mathrm{~J} / \mathrm{g}$ for $\mathrm{P}(3 \mathrm{HB}-\mathrm{co}-12 \mathrm{~mol} \% 3 \mathrm{HV}) ; T_{\mathrm{g}}$ were $1,-1$ and $-2^{\circ} \mathrm{C}$ for $\mathrm{P} 3 \mathrm{HB}, \mathrm{P}(3 \mathrm{HB}-\mathrm{co}-5 \mathrm{~mol} \%$ $3 \mathrm{HV})$ and $\mathrm{P}(3 \mathrm{HB}-\mathrm{co}-12 \mathrm{~mol} \%$ 3HV), respectively. 
The molecular weights $(M \mathrm{w})$ and polydispersity index $(M \mathrm{w} / M \mathrm{n})$ determined by GPCMALLS of PHAs samples produced by P.guezennei are listed in Table 1. Molecular weights ranged from $64000 \mathrm{~g} / \mathrm{mol}$ on oleic acid to $390000 \mathrm{~g} / \mathrm{mol}$ on octanoate. Polydispersity values were lower than 2 under all conditions, indicative of the uniform formation of PHAs within the cell cytoplasm.

The ${ }^{1} \mathrm{H}$ NMR spectrum of PHAs MCL obtained from P.guezennei on oleic acid showed the signals of the methine protons $(\mathrm{CH})$ at $5.2 \mathrm{ppm}\left(\mathrm{Fig}\right.$. 2). The triplet resonance $\left(\mathrm{J}_{\mathrm{HH}}\right.$ $=6.7 \mathrm{~Hz})$ at $0.88 \mathrm{ppm}$ was assigned to the terminal methyl group $\left(\mathrm{CH}_{3}\right)$, and the multiplet resonance at 2.47-2.58 ppm to the methylene protons $\left(\mathrm{CH}_{2}\right)$ of C-2 carbon atom. The methylene protons of the $\mathrm{C} 4$ carbon atom yielded a signal at $1.58 \mathrm{ppm}$, while all other methylene hydrogens of the saturated side chains produced a signal at 1.26 ppm. The signals at 5.35 and $5.5 \mathrm{ppm}$ in the ${ }^{1} \mathrm{H}$ spectrum were assigned to the protons of a double bond, while those at 2 and $2.35 \mathrm{ppm}$ corresponded to methylene protons linked to double bonds. Signals of the ${ }^{13} \mathrm{C}$ spectrum at $123 \mathrm{ppm}$ and $134 \mathrm{ppm}$ also indicated the presence of unsaturated units (data not shown).

GC-MS analyses of TMSi derivatives of PHAs allowed us to determine the monomeric composition of the PHAs obtained from P. guezennei cultivated on different carbon substrates. The mass spectra of TMSi derivatives of 3-hydroxyalkanoic acids exhibited characteristic fragments $\left[\left(\mathrm{CH}_{3}\right)_{3} \mathrm{SiO}^{+}=\mathrm{CHCH}_{2} \mathrm{CO}_{2} \mathrm{CH}_{3}\right]$ at $m / z \quad 175$ and $\left[\mathrm{RCH}=\mathrm{O}^{+} \mathrm{Si}\left(\mathrm{CH}_{3}\right)_{3}\right]$ at $\mathrm{m} / z,[\mathrm{M}-73]$ resulting from $\alpha$-cleavage of the derivatized hydroxyl group (Fig. 3). The TMSi ethers do not usually show a parent molecular ion but the molecular ion related fragment at $m / z$ [M-15] is quite prominent and can be used to determine the chain length of monomers (i.e 259 for 3-hydroxydecanoate (3HD), 285 for 3-hydroxydodecenoate (3HDde)); The existence of a double-bond can be deduced 
from the molecular weight of the fragment at $m / z$ [M-15] which is two amu less than that of the corresponding saturated monomer, and from the weak intensity ratio of the peak at $m / z$ [M-15] to the base peak. Others fragments of lower mass were also common for the 3-hydroxyl functional group and readily assignable : $m / z 73\left[\left(\mathrm{CH}_{3}\right)_{3} \mathrm{Si}^{+}\right], m / z 89$ $\left[\left(\mathrm{CH}_{3}\right)_{3} \mathrm{SiO}^{+}\right], m / z, 131\left(\mathrm{C}_{5} \mathrm{H}_{11} \mathrm{SiO}_{2}\right)^{+}, m / z, 159\left(\mathrm{C}_{6} \mathrm{H}_{11} \mathrm{SiO}_{3}\right)^{+}$and $m / z, 133\left(\mathrm{C}_{5} \mathrm{H}_{13} \mathrm{SiO}_{2}\right)^{+}$.

\subsection{Effect of substrates on synthesis of PHAs by P.guezennei}

The composition of PHAs synthesized by P.guezennei on different carbon substrates is summarized in Table 2. The purified copolymers contained at least six different monomers. P. guezennei synthesized PHAs containing C4 to C14 3-hydroxyacids when grown on the different substrates. When glucose was used as the sole carbon source, P.guezennei synthesized a PHAs MCL containing mainly 3-hydroxydecanoate (3HD) and 3-hydroxyoctanoate (3HO) monomeric units accounting for 62.8 and $22 \mathrm{~mol} \%$ respectively. The monomeric composition of PHAs produced by P.guezennei from acetate or pyruvate were similar with $3 \mathrm{HD}$ and $3 \mathrm{HO}$ predominating. Cells cultivated on propionate or valerate accumulated PHAs with a more complex composition. On hexanoate, heptanoate or octanoate, PHAs obtained from P. guezennei consisted primarily of 3-hydroxyhexanoate $(3 \mathrm{HHx}), 3$-hydroxyheptanoate $(3 \mathrm{HHp})$ and $3 \mathrm{HO}$, respectively. Cells grown on oleic acid accumulated PHA containing equal amounts of $3 \mathrm{HO}$ and $3 \mathrm{HD}$ along with significant proportions of longer chains such as 3hydroxydodecanoate (3HDd) (11 mol\%) and monounsaturated 3-hydroxytetradecenoate (3HTde) (13.8 mol\%). 
During cultivation with a combination of fatty acid and glucose, $P$. guezennei accumulated a polymer whose composition reflected the structure of the fatty acid substrate. For example, when the culture medium contained both glucose and octanoate, P. guezennei produced a PHA with a structure that resembled the one of the polymer obtained on octanoate. Similarly, cells cultivated in medium containing a mixture of hexanoic acid and glucose accumulated polymer that contained $26.5 \mathrm{~mol} \%$ more of $3 \mathrm{HHx}$ and $36 \mathrm{~mol} \%$ more of $3 \mathrm{HO}$ compared to polymer accumulated on glucose only. Moreover, a large fraction of monomers were one or more two-carbon units longer than the substrate. When hexanoate served as carbon source, the resulting polymer contained $61 \mathrm{~mol} \%$ of $3 \mathrm{HO}, 6.3 \mathrm{~mol} \%$ of $3 \mathrm{HD}$ and $6.3 \mathrm{~mol} \%$ of $3 \mathrm{HDd}$ monomers along with 31.5 mol\% of the $3 \mathrm{HHx}$ monomer. When heptanoate served as carbon source, the polymer contained significant amount of 3-hydroxynonanoate (3HN) (10.7 mol\%), and less amount of 3-hydroxyundecanoate (3HUD) (1.4 mol\%).

At the opposite, during growth on octanoate and heptanoate, a portion of the polymer contained monomers that were two-carbon units less than the original substrate i.e 4.3 mol\% of 3HHx and 4 mol\% of 3-hydroxypentanoate (3HP) respectively.

In bacteria, there are three main pathways involved in the synthesis of PHAs MCL precursors. Fatty acid oxidation by $\beta$-oxidation is the main route when fatty acids are supplied as exogenous substrates, de novo fatty acid biosynthesis is the main pathway when simples compounds such as glucose and acetate are supplied as exogenous substrates, and chain elongation occurs via acyl-Co-A derived from acetyl-Co-A [18, 28]. The results obtained from P. guezennei cultivated on fatty acids clearly evidenced the effect of fatty acid structure on PHAs composition, with a great proportion of 
repeating units with the same number of carbon as the fatty acid supplied. Subunits containing two carbon atoms less or more than the carbon source were also detected in significant quantities in the polymer. The presence of subunits containing two carbon atoms shorter than the fatty acid substrate is common when the cells employ the fatty acid $\beta$-oxidation pathway as the main route for PHAs synthesis. Under these conditions, fatty acids are converted to the corresponding acyl-Co-A thioesters and oxidized by fatty acid $\beta$-oxidation via trans-2-enoyl-Co-A and (S)-3-hydroxyacyl-Co-A to 3ketoacyl-Co-A, which is cleaved by a $\beta$-ketothiolase to acetyl-Co-A and acyl-Co-A. This pathway yields subunits that contain two carbon atoms less than the acyl-Co-A that entered the first cycle. These intermediates of the $\beta$-oxidation cycle are withdrawn and enzymatically converted into (R)-3-hydroxyacyl-Co-A, which then serves as the substrate for PHA synthase $[6,7,14,16,29]$. In our study, the presence of $3 \mathrm{HP}$ and 3HHx monomers in PHAs accumulated in $P$. guezennei grown respectively on heptanoate and octanoate clearly demonstrates that $P$. guezennei degraded fatty acids by $\beta$-oxidation and synthesized these (R)-3-hydroxyacyl-Co-A monomers from the intermediates of this pathway.

During growth on simple compounds such as glucose and acetate, P. guezennei synthesized a PHAs MCL mainly composed of $3 \mathrm{HD}$ and $3 \mathrm{HO}$ monomers. As with glucose, acetate is converted to acetyl-Co-A that serves as a precursor for PHAs biosynthesis via the de novo fatty acid biosynthesis route. Moreover, the presence of monomers differing by two carbon atoms as well as the presence of constituents with more than 10 carbon atoms with unsaturated bonds clearly reflects the use of the fatty acid de novo biosynthesis pathway as the source of intermediates for PHA synthesis. Precursors for fatty acid biosynthesis are derived from the acetyl-Co-A pool, generated 
from several substrates including carbohydrates. Acetyl-Co-A is first converted to alonyl-CO-A which is used to elongate the fatty acid carbon chain in two carbon atom increments; an acyltransferase allows the transfer of the hydroxyacyl moiety from (R)3-hydroxy-acyl Acyl Carrier Protein (ACP) to co-enzyme A, forming (R)-3-hydroxyacyl-Co-A, a substrate for PHA synthase [7]. Thus, intermediates containing 4, 6, 8, $10 \ldots$ carbon atoms are progressively synthesized. A key-enzyme, $\beta$-hydroxydecanoylACP dehydrase, allows the divergence of saturated and unsaturated constituents with 12 or more carbon atoms. This is consistent with the composition of PHAs MCL that accumulated in glucose-grown cells, which consisted of $1.3 \mathrm{~mol} \% 3 \mathrm{HB}, 0.9 \mathrm{~mol} \%$ 3HHx, 22mol\% 3HO, $62.8 \mathrm{~mol} \%$ 3HD, $6.2 \mathrm{~mol} \%$ 3HDd, $5.6 \mathrm{~mol} \%$ 3HDde and 1.2 mol\% 3HTD.

It appears therefore that $P$. guezennei is capable of producing acetate from the $\mathrm{n}$ alkanoic acid carbon source by $\beta$-oxidation, which is then used to build longer chain length compounds by addition to the original substrate or to other intermediates. The presence of monomers with a larger chain length than the substrate has already been observed in other pseudomonas $[13,16,19,30,31]$. As in previous work, the polymerizing enzyme system of $P$. guezennei appears to have a preference for monomers with 8 or 10 carbon atoms that are always present and often dominant, while larger and smaller monomers are incorporated less efficiently [13, 19, 31]. This might explain why the C8 and C10 monomers occur in PHAs even when cells are cultivated in the presence of substrates with shorter chain lengths.

\section{Conclusions}


This study showed that P.guezennei, a recently described bacteria isolated from a microbial mat, is able to synthesize PHAs ${ }_{\text {MCL }}$ copolymers with a variety of structures and properties ie saturated and unsaturated monomers containing from 4 to 14 carbon atoms, with a preference for $\mathrm{C} 8$ and $\mathrm{C} 10$ monomers. Our results clearly demonstrate the capability of P.guezennei to use a wide variety of carbon sources, fatty acid or carbohydrates, making P.guezennei an interesting candidate for the production of PHAs from by-products of many industries, thus resulting in a reduction of the cost production of these biopolyesters. Moreover, PHAs containing unsaturated monomers can be further modified by chemical reactions such as cross-linking, double bond hydration, epoxidation...to produce new polymers having different thermal and mechanical properties. Chemical modification of biosynthetic PHAs is a promising approach to expend bacterial polyesters to be used in the medical and environmental areas.

\section{References}

[1] G. Braunegg, G. Lefebvre, K.F. Genser, J. Biotechnol. 65 (1998) 127.

[2] C.R. Hankermeyer, R.S Tjeerdema, Rev. Environ. Contam. Toxicol. 159 (1999) 1.

[3] P.J. Hocking, R.H. Marchessault, Biopolyesters, Chemistry and Technology of Biodegradable Polymers, Blackie Academic and Professional, 1994.

[4] A. Steinbüchel, H.E. Valentin, FEMS Microbiol. Lett. 128 (1995) 219.

[5] A.J. Anderson, E.A. Dawes, Microbiol. Rev. 54 (1990) 450.

[6] Y. Doi. Microbial Polyesters, VHC Publishers, New-York, 1990.

[7] A. Steinbüchel, T. Lütke-Eversloh, Biochem. Engineer. J. 16 (2003) 81.

[8] R.D. Ashby, D.K.Y. Solaiman, T.A. Foglia, J. Polym. Environ. 12 (2004) 105.

[9] R.D. Ashby, D.K.Y. Solaiman, T.A. Foglia, Biomacromolecules 6 (2005) 2106. 
[10] M. Koller, R. Bona, G. Braunegg, C. Hermann, P. Horvat, M. Kroutil, J. Martinez, J. Neto, L. Pereira, P. Varila, Biomacromolecules 6 (2005) 561.

[11] D.K.Y. Solaiman, R.D. Ashby, T.A. Foglia, Appl. Microbiol. Biotechnol. 56 (2001) 664.

[12] T. Tsuge, J. Bioscience Bioengin. 94 (2002) 579.

[13] G.W. Huisman, O. De Leeuw, G. Eggink, B. Witholt, Appl. Environ. Microbiol. 55 (1989) 1949.

[14] R.G. Langeveen, G.W. Huisman, H. Preusting, P. Ketelaar, G. Eggink, B. Witholt, Appl. Environ. Microbiol. 54 (1988) 2924.

[15] A. Timm, A. Steinbüchel, Appl. Environ. Microbiol. 56 (1990) 3360.

[16] H. Brandl, R.A. Gross, R.W. Lenz, R.C. Fuller, Appl. Environ. Microbiol. 54 (1988) 1977.

[17] G.W. Haywood, A.J. Anderson, D.F. Ewing, E.A. Dawes, Appl. Environ. Microbiol. 56 (1990) 3354.

[18] G.N.M. Huijberts, G. Eggink, P. De Waard, G.W. Huisman, B. Witholt, Appl. Environ. Microbiol. 58 (1992) 536.

[19] G.N.M Huijberts, T.C. De Rijk, P. De Waard, G. Eggink, J. Bacteriol. 176 (1994) 1661.

[20] C. Simon-Colin, K. Alain, J. Cozien, B. Costa, J. Guezennec, G. Raguénès, J. Appl. Microbiol. (2007) Pulished online.

[21] P.G. Barham, A. Keller, E.L. Otum, A. Holmes, J. Mater. Sci. 19 (1984) 2781.

[22] N. Yoshie, Y. Oike, K.I. Kasuya, Y. Doi, Y. Inoue, Biomacromolecules 3 (2002) 1320. 
[23] S. Bayari, F. Severecan, J. Mol. Struct. 744 (2005) 529.

[24] S. Randriamahefa, E. Renard, P. Guérin, V. Langlois, Biomacromolecules 4 (2003) 1092.

[25] N. Galego, C. Rozsa, S. Sanchez, J. Fung, A. Vasquez, J.S. Tomas, Polym. Test. $19(2000) 485$.

[26] T. Fukui, H. Abe, Y. Doi, Biomacromolecules 3 (2002) 618.

[27] I-C. Ho, S-P. Yang, W-Y Chiu, S-Y. Huang, Int. J. Biol. Macromol. 40 (2007) 112.

[28] S. Klinke, Q. Ren, B. Witholt, B. Kessler, Appl. Environ. Microbiol. 65 (1999) 540.

[29] G. Eggink, H. van der Wal, G.N.M. Huijberts, Production of poly-3hydroxyalkanaotes by Pseudomonas putida during growth on long-chain fatty acids. In E.A Dawes (Ed.) Novel Biodegradable Polymers, NATO ASI Series, Kluwer Academic Publishers, Dordrecht, The Netherlands, 1990.

[30] R.A. Gross, C. DeMello, R. Lenz, H. Brandl, F.C. Fuller, Macromolecules 22 (1989) 1106.

[31] N. Tackor, U. Trivedi, K.C. Patel, Biores. Technol. 96 (2005) 1843. 


\section{Figure legends}

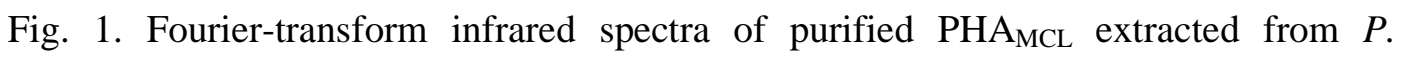
guezennei grown on glucose (a) and on oleic acid (b).

Fig. 2. ${ }^{1} \mathrm{H}$ NMR spectra of purified PHAs obtained from $P$. guezennei during cultivation on oleic acid.

Fig. 3. Mass spectra of the TMSi derivatives of 3-hydroxydecanoic acid (3HD) (a) and 3-hydroxydodecenoic acid (3HDde) (b) methyl esters. The characteristic peaks and molecular ion-related fragments were assigned as described in the text. 


\section{Table footnotes}

Table 1

$T_{\mathrm{m}}, T_{\mathrm{g}}, \Delta H_{\mathrm{m}}, \mathrm{CI}$, and molecular weight of PHAs obtained from P. guezennei grown on various substrates.

Table 2

Characterization of PHAs obtained from $P$. guezennei grown on various substrates. 
Figure $1 \mathrm{~b}$
Click here to download high resolution image

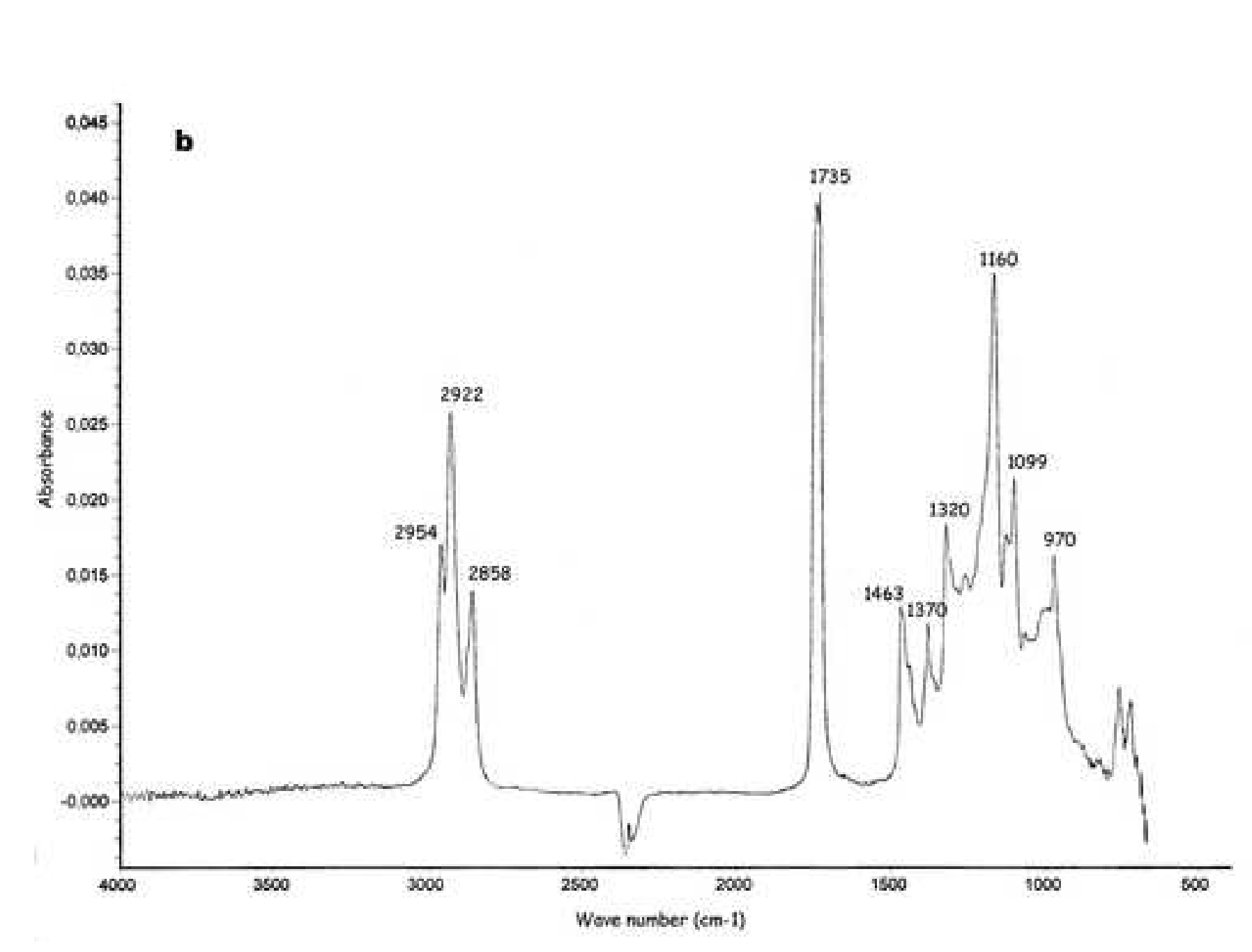

Click here to download high resolution image

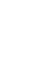


Click here to download high resolution image

b

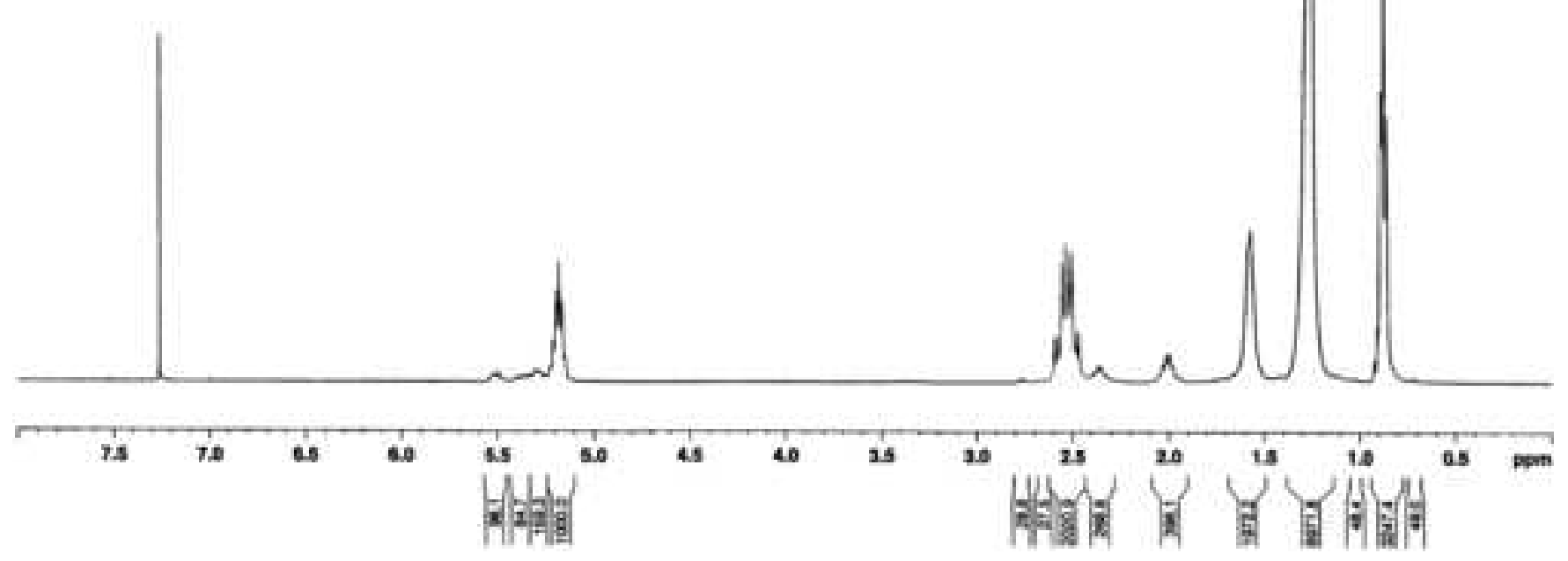


Click here to download high resolution image

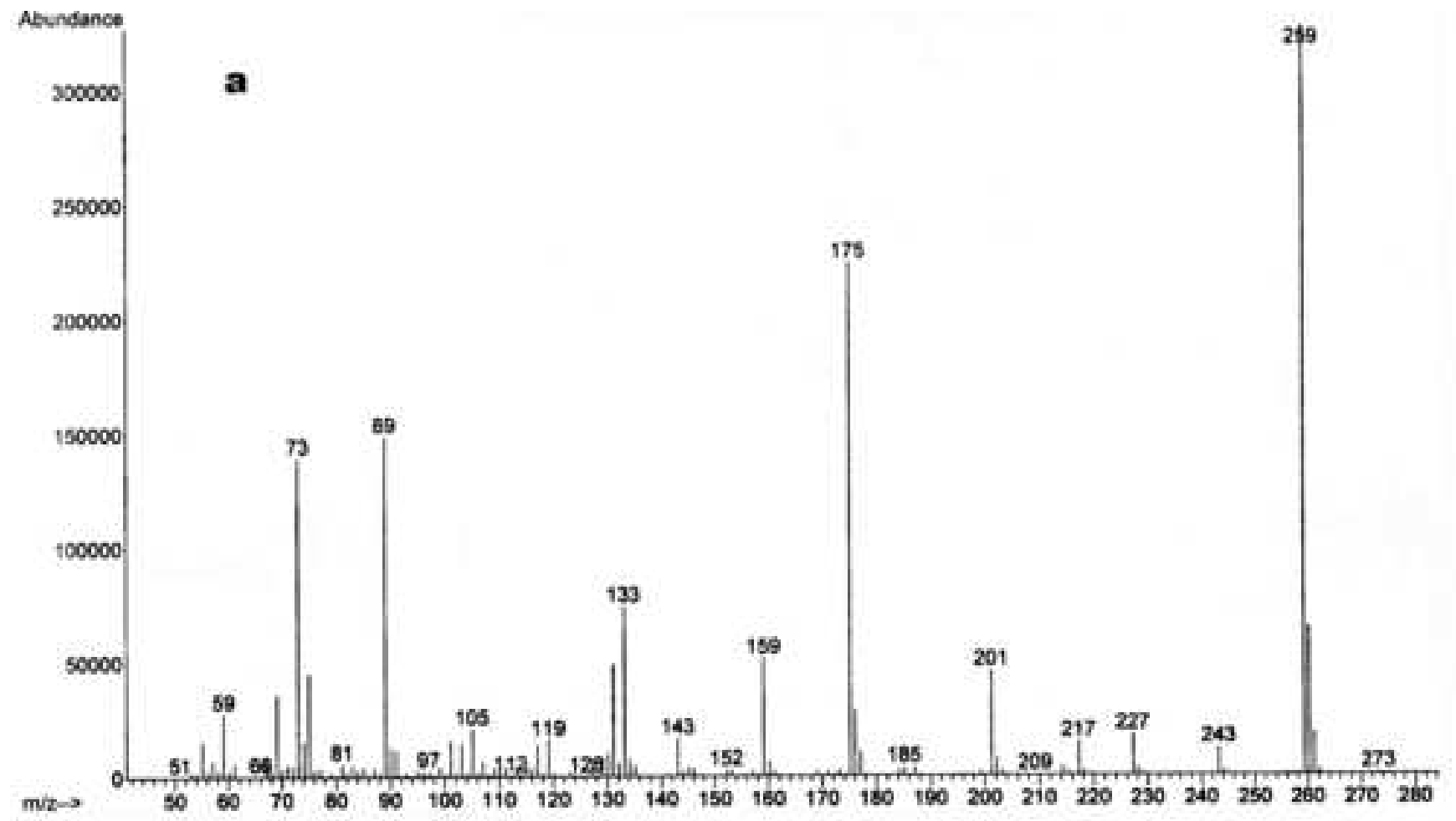


Figure $3 b$
Click here to download high resolution image

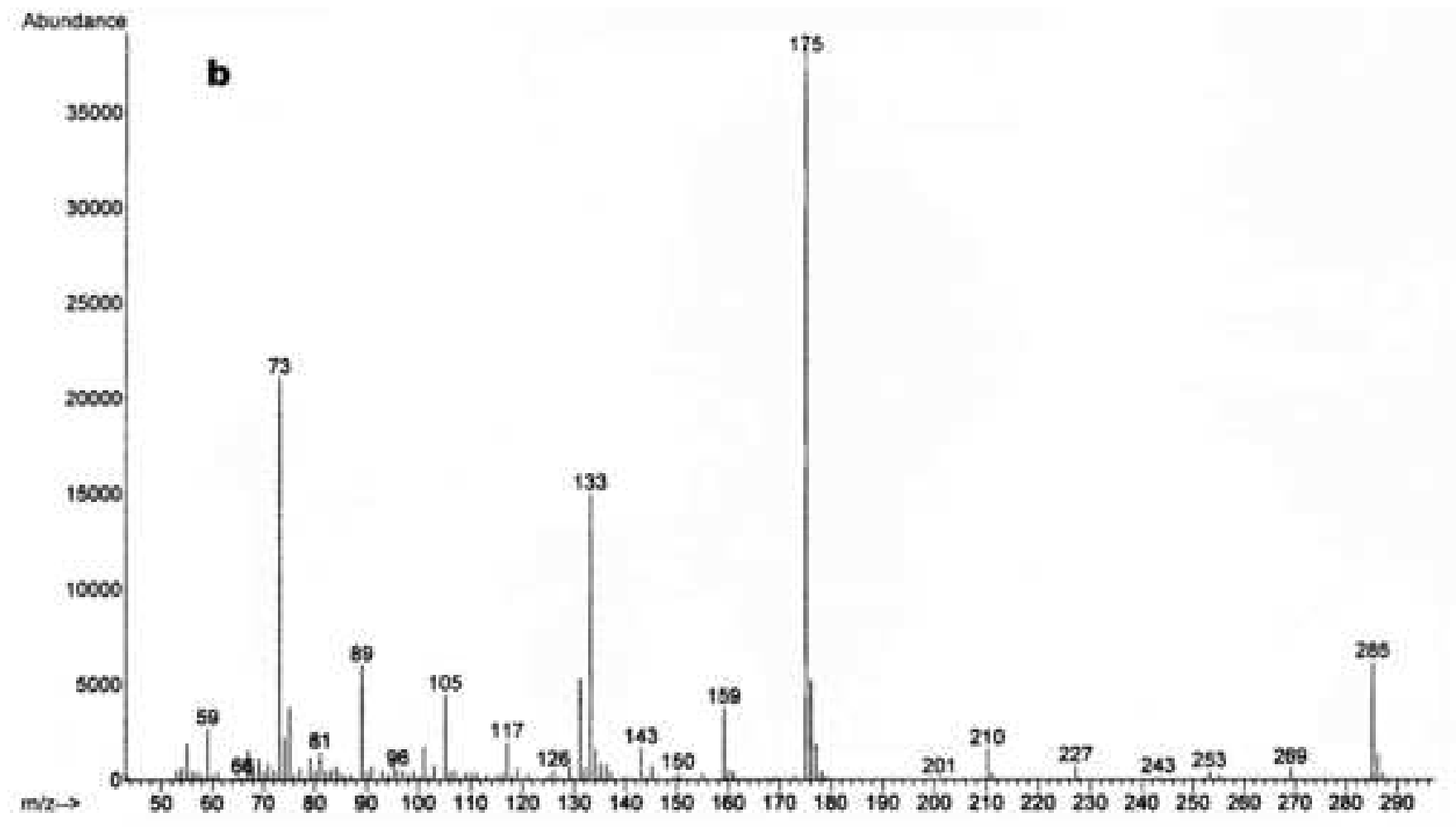


Table 1

$T_{\mathrm{m}}, T_{\mathrm{g}}, \Delta H_{\mathrm{m}}, \mathrm{CI}$, and molecular weight of PHAs obtained from $P$. guezennei grown on various substrates.

\begin{tabular}{|c|c|c|c|c|c|c|}
\hline $\begin{array}{l}\text { Carbon } \\
\text { substrate }\end{array}$ & $T_{\mathrm{m}}\left({ }^{\circ} \mathrm{C}\right)$ & $T_{\mathrm{g}}\left({ }^{\circ} \mathrm{C}\right)$ & $\Delta H_{\mathrm{m}}(\mathrm{J} / \mathrm{g})$ & $\mathrm{Cl}$ & $\begin{array}{l}M \mathrm{w} \\
(\mathrm{g} / \mathrm{mol})\end{array}$ & $M w / M n$ \\
\hline Glucose & 49 & -44 & 19 & 0.28 & 119000 & 1.85 \\
\hline Ac & 48 & -47 & 16 & 0.26 & 180000 & 1.7 \\
\hline Pyr & 47 & -45 & 11 & 0.23 & 168000 & 2 \\
\hline Prop & 42 & -49 & 13 & 0.37 & 167000 & 1.93 \\
\hline Val & 42 & -41 & 11 & 0.32 & 122000 & 1.85 \\
\hline Hexanoate & 49 & -42 & 7 & 0.29 & 180000 & 1.7 \\
\hline Heptanoate & 46 & -41 & 6 & 0.27 & 180000 & 1.7 \\
\hline Octanoate & 46 & -49 & 13 & 0.26 & 390000 & 1.66 \\
\hline Oleic acid & 40 & -43 & 6 & 0.32 & 64200 & 1.8 \\
\hline Glucose + Acetate & 47 & -50 & 22 & 0.31 & 141000 & 1.75 \\
\hline Glucose + Pyruvate & 48 & -43 & 18 & 0.31 & 222000 & 1.86 \\
\hline Glucose + Propionate & 47 & -46 & 14 & 0.3 & 206000 & 1.6 \\
\hline Glucose + Octanoate & 51 & -42 & 4 & 0.27 & 241000 & 1.86 \\
\hline Glucose + Hexanoate & 49 & -45 & 11 & 0.31 & 275000 & 2 \\
\hline Pyruvate + Propionate & 44 & -42 & 14 & 0.32 & 220000 & 2.1 \\
\hline Acetate + Propionate & 44 & -45 & 18 & 0.36 & 250000 & 1.9 \\
\hline Pyruvate + Octanoate & 45 & -48 & 13 & 0.24 & 256000 & 1.88 \\
\hline
\end{tabular}



Table 2

Characterization of PHA s obtained from P. guezennei grown on various substrates.

\begin{tabular}{|c|c|c|c|c|c|c|c|c|c|c|c|c|}
\hline $\begin{array}{l}\text { Carbon } \\
\text { substrate }\end{array}$ & $3 \mathrm{HB}$ & 3HP & $3 \mathrm{HHx}$ & 3HНp & $3 \mathrm{HO}$ & $3 \mathrm{HN}$ & 3HD & 3HUD & 3HDd & 3HDde & 3HTD & 3HTde \\
\hline Glucose & 1,3 & & 0,9 & & 22 & & 62.8 & & 6.2 & 5.6 & 1.2 & \\
\hline Ac & 0.3 & & 0.9 & & 20.6 & & 68.3 & & 4.6 & 5.3 & & \\
\hline Pyr & & & 0.4 & & 16.3 & & 73 & & 4 & 6.3 & & \\
\hline Prop & 0.2 & 0.2 & 1 & 1.9 & 19.4 & 9.6 & 54.2 & 4 & 4.5 & 5 & & \\
\hline Val & 0.2 & 10.6 & 0.7 & 14 & 12.5 & 10.3 & 41.2 & 3.5 & 2.8 & 4.2 & & \\
\hline Hexanoate & 0.6 & & 31.5 & & 61 & & 6.3 & & 6.3 & & & \\
\hline Heptanoate & 0.1 & 4 & & 74.2 & 3.2 & 10.7 & 5.2 & 1.4 & 0.5 & 0.7 & & \\
\hline Octanoate & 0.1 & & 4.3 & & 92.3 & & 2.8 & & 0.4 & 0.5 & & \\
\hline Oleic acid & 0.3 & & 2 & & 37.7 & & 35.6 & & 11 & 1.7 & 1.9 & 13.8 \\
\hline Glucose + Acetate & 0.3 & & 1 & & 22 & & 65 & & 4.7 & 7 & & \\
\hline Glucose + Pyruvate & 1.2 & & 1.3 & & 25.6 & & 63.7 & & 3.8 & 4.4 & & \\
\hline Glucose + Propionate & & 0.1 & 0.6 & 2.5 & 16.5 & 14.8 & 48 & 7 & 4.8 & 5 & & 0.7 \\
\hline Glucose + Octanoate & 0.1 & & 4.5 & & 92 & & 2.6 & & 0.4 & 0.4 & & \\
\hline Glucose + Hexanoate & 0.9 & & 27.4 & & 58 & & 6.5 & & 6 & & 1.2 & \\
\hline Pyruvate + Propionate & 0.6 & & 1.5 & 3 & 19.9 & 10.9 & 42.5 & 5.2 & 5.5 & 10.9 & & \\
\hline Acetate + Propionate & 0.3 & 0.3 & 1 & & 18 & 6.4 & 58 & 2 & 8 & 6 & & \\
\hline Pyruvate + Octanoate & 0.2 & & 5.1 & & 90 & & 4.7 & & & & & \\
\hline
\end{tabular}

A bbreviations used: 3HB (3-hydroxybutyrate), 3H (3-hydroxypentanoate), 3H Hx (3-hydroxyhexanoate), 3H Hp (3-hydroxyheptanoate), 3HO (3-hydroxyoctanoate), 3H N (3hydroxynonanoate), 3HD (3-hydroxydecanoate), 3HUD (3-hydroxyundecanoate), 3HDd (3-hydroxydodecanoate), 3HDde (3-hydroxydodecenoate), 3HTD (3hyydroxytetradecanoate), 3HTde (3-hydroxytetradecenoate) 